\section{OPEN ACCESS}

Edited by:

Stefania Bortoluzzi,

University of Padova, Italy

Reviewed by:

Yi Miao,

Nanjing Medical University, China

Stefan Hohaus,

Catholic University of the Sacred

Heart, Rome, Italy

*Correspondence:

Sabino Ciavarella

s.ciavarella@oncologico.bari.it

Specialty section

This article was submitted to Hematologic Malignancies,

a section of the journa

Frontiers in Oncology

Received: 08 January 2020

Accepted: 27 February 2020

Published: 31 March 2020

Citation:

Opinto G, Vegliante MC, Negri A,

Skrypets T, Loseto G, Pileri SA, Guarini A and Ciavarella S (2020) The Tumor Microenvironment of DLBCL in the Computational Era.

Front. Oncol. 10:351.

doi: 10.3389/fonc.2020.00351

\title{
The Tumor Microenvironment of DLBCL in the Computational Era
}

\author{
Giuseppina Opinto ${ }^{1}$, Maria Carmela Vegliante ${ }^{1}$, Antonio Negri ${ }^{1}$, Tetiana Skrypets ${ }^{1,2}$, \\ Giacomo Loseto ${ }^{1}$, Stefano Aldo Pileri ${ }^{3}$, Attilio Guarini ${ }^{1}$ and Sabino Ciavarella ${ }^{1 *}$ \\ ${ }^{1}$ Unit of Hematology and Cell Therapy, Laboratory of Hematological Diagnostics and Cell Characterization, Istituto Tumori \\ "Giovanni Paolo II"-IRCCS, Bari, Italy, ${ }^{2}$ CHIMOMO Department, University of Modena and Reggio Emilia, Modena, Italy, \\ ${ }^{3}$ Division of Haematopathology, European Institute of Oncology - IRCCS, Milan, Italy
}

Among classical exemplifications of tumor microenvironment (TME) in lymphoma pathogenesis, the "effacement model" resembled by diffuse large B cell lymphoma (DLBCL) implies strong cell autonomous survival and paucity of non-malignant elements. Nonetheless, the magnitude of TME exploration is increasing as novel technologies allow the high-resolution discrimination of cellular and extra-cellular determinants at the functional, more than morphological, level. Results from genomic-scale studies and recent clinical trials revitalized the interest in this field, prompting the use of new tools to dissect DLBCL composition and reveal novel prognostic association. Here we revisited major controversies related to TME in DLBCL, focusing on the use of bioinformatics to mine transcriptomic data and provide new insights to be translated into the clinical setting.

Keywords: tumor microenvironment, transcriptomics, deconvolution, prognostication, DLBCL

\section{INTRODUCTION}

Diffuse large B cell lymphoma (DLBCL) has long been regarded as a paradigm of aggressive diseases composed of malignant B cells dividing rapidly and independently of stimuli from the surrounding tumor microenvironment (TME) (1). Over the last few years, evolving technologies enabling deeper genomic and transcriptomic profiling revealed an underestimated complexity of DLBCL biology, involving both the malignant and non-malignant compartments of the disease.

Seminal gene expression profiling (GEP) studies showed striking associations between expression of genes reflecting tumor cell-of-origin $(\mathrm{COO})$ and outcomes to standard immuno-chemotherapy (2). Two distinct molecular categories, germinal center B cell and activated $B$ cell $(A B C)$, were incorporated in the revised WHO classification of DLBCL (2). The development of immunohistochemistry (IHC) algorithms to surrogate GEP was promptly followed by the commercialization of a gene panel for proper $\mathrm{COO}$ determination (3). The assessment of the transcriptional, rather than phenotypical, features of DLBCL also resulted in a remarkable improvement of survival prediction. With the advent of new technologies, such as NanoString, the digital gene expression measurement on formalin-fixed paraffin-embedded (FFPE) biopsies facilitated the inclusion of $\mathrm{COO}$ categorization in daily clinical practice (3). However, very recent integrative analyses by whole-exome and transcriptome sequencing brought DLBCL genetics to a new level (4-6), identifying molecular categories within COO classification characterized by distinct drivers with novel prognostic and therapeutic implications.

While a substantial amount of information from these studies is being translated into the clinic, results capturing the molecular aspects of TME are still under debate. Historical GEP 
analyses provided alternative categorization of DLBCL based on the differential expression of genes reflecting inflammatory host response and oxidative metabolism (7) or enrichment in peculiar immune and extra-cellular determinants (8). Such observation remained poorly applied on clinical ground owing to an incomplete comprehension of the specific cellular/molecular TME determinants and the precise mechanisms of their prognostic impact. In a recent translational effort, our group exploited a computational approach to reinterpret large transcriptional data and provide a pure TME-based prognosticator that improves the COO risk stratification (9). Latest results from sequencing studies and clinical trials on new drugs (i.e., lenalidomide and ibrutinib) underscored the relevance of studying DLBCL heterogeneity, taking into proper account the impact of TME in diagnostics, prognostics, and therapeutic prediction.

We reviewed current controversies related to TME in DLBCL, with particular emphasis on recent computational strategies capturing new microenvironmental features, at both the cellular and the molecular levels.

\section{EVOLVING TECHNOLOGIES TO FACE TME-RELATED CONTROVERSIES}

About 20 years ago, the first GEP-scale analysis of de novo nodal DLBCL not otherwise specified demonstrated that morphological approaches, even supplemented by IHC, were incapable of capturing divergent molecular modules between tumors, and identified two main subgroups resembling the diverse stage of B cell differentiation with a different prognosis (10). Each subgroup also showed consistent transcriptomic heterogeneity of non-malignant compartment. The expression level of many genes reflected a variable extent of $\mathrm{T}$ cell (TCR-beta, CD3e, Fyn, LAT, PKC-u), monocyte/macrophages (CD14, CD105, CSF$1 R$, FcR-gamma), and natural killer (NK4) infiltration as well as extracellular matrix (ECM) remodeling by metalloproteinases (i.e., MMP9 and TIMP), integrins, chemokines, and other stromal axes (i.e., CXCR4/SDF-1). Assembled in the so-called lymph node (LN) signature, these genes were shared by samples of normal lymph nodes and tonsil (10), remarking their structural and immune function within secondary lymphoid organs (SLO) (11). A second large genome-scale study highlighted a direct correlation between the expression of the LN signature and a better outcome after $\mathrm{CHOP}$ chemotherapy, emphasizing that the $\mathrm{ABC}$ subgroup had the lowest enrichment of genes in the signature (12). Their expression was also inversely related to a "proliferation" signature including genes regulating malignant growth processes and BMP-6, a single TGF-related mesenchymal gene associated with poor outcome. Once again, stromal factors implicated in ECM organization and shared by elements of innate immunity, especially macrophages (Mo), dendritic cells (DC), and NK, were involved in the physiopathology and drug response of DLBCL. This observation was partially confirmed by Monti et al. (7) who identified a "host response" gene set in DLBCL, showing a coordinated activation of inflammatory response driven by $\mathrm{CD}^{+} \mathrm{T}$ cells, DC, Mo, and NK, adhesion axes (LFA-1,
PECAM-1, and SDF-1), cytokine/chemokine stimuli (especially IFN and TNF $\alpha$ ), and ECM components (i.e., collagens). However, the patients in this cluster did not show any therapeutic advantage following CHOP chemotherapy. A subsequent work by Lenz et al. (8) definitely recognized a "stromal" signature related to the sorted CD19-negative non-malignant component, reflecting high deposition of ECM proteins, as fibronectin (FN), secrete protein acid rich in cysteine (SPARC), and various collagen isoforms and prevalent infiltration of cells of myelomonocytic lineages. DLBCL expressing this signature showed longer survival after R-CHOP independently of COO, suggesting an intriguing stromal protection and raising the question on whether the abundance of histiocytes prompts the tumor cell killing by rituximab.

Beyond their relevance in characterizing the tumor cell fraction, GEP results strengthened the idea that finely regulated interconnections between mesenchymal (stromal) and hematopoietic (immune) counterparts in SLO govern the extent of inflammatory reactions as the tumor evolves. Such underestimated mechanisms were likely independent of $\mathrm{COO}$ and seemed to underlie the inter-patient diversity in drug responsiveness. Measuring selected TME genes by RNA microarrays, however, remained mechanistically uninformative and, although of certain prognostic utility, was hampered by cost, standardization issues, and scarce availability of freshfrozen biopsy material. Great translational efforts, in fact, were devoted at surrogating GEP by flow cytometry or IHC and localizing cellular contributors of TME-based prognostication directly on FFPE material. In situ staining of matricellular proteins, such as FN, SPARC, and collagens, as well as IHC or immunofluorescence (IF) quantification of tumor-infiltrating lymphocytes and other immune cells (13-17) provided results partially in line with GEP, but highly controversial due to their low reproducibility and questionable validation. They further underscored that the static pictures of protein or surface marker expression are inadequately representative of the transcriptional dynamism that controls TME components at functional rather than phenotypic level. This aspect is particularly critical for Mo and explains their controversial role in DLBCL prognostication (18). When measured by the sole CD68 IHC staining, the extent of tumor infiltration by Mo appeared significantly associated with an adverse outcome to CHOP therapy only in the study by Cai et al. (19), whereas it had no prognostic value in other studies $(13,20,21)$. Conversely, CD68 at both the RNA and the protein levels was found to have a positive prognostic impact in patients treated by rituximab plus CHOP (22). Co-staining of CD68 and CD163-capturing putative immunosuppressive Mo with a M2-like phenotype-correlated with shorter survival in R-CHOP-treated cohorts (23-25), whereas the prevalence of either M1-like $\mathrm{CD}^{+} 8^{+} / \mathrm{HLA}_{-} \mathrm{DR}^{+} \mathrm{Mo}(24)$ or M2-like $\mathrm{CD} 163^{+}$ cells in similar studies did not show any significant prognostic association (22). Such discrepancies not only were mainly due to differences in staining techniques, antibody clones, patient cohorts, and treatments, but also imply that simple detection of surface molecules does not surrogate the extreme in vivo functional plasticity of Mo. Recently, a "lymphomaassociated Mo interaction gene" signature (LAMIS) was built 
on pooled GEP datasets and associated to shorter PFS and OS in a large cohort of R-CHOP/R-CHOP-like-treated patients, independently of COO and IPI status (26). However, beyond prognostic implications, a fundamental comprehension of Mo biology is still lacking, probably due to insufficient technology to disentangle their quantitative, functional, and phenotypic dynamics within the DLBCL milieu.

On the other hand, as the access to huge amounts of transcriptomic data from bulk tissues became available, the application of new computational tools allowed unprecedented degrees of TME exploration. The deconvolution of GEP or RNA sequencing (RNA-seq) data was shown to provide simultaneous information about quantitative proportions of non-malignant cell types and their transcriptional states, uncovering potential prognostic and therapeutic associations (27-29). In a direct experience of our group, publicly available GEP datasets, including the one by Lenz et al. (8), were analyzed by CIBERSORT (27) to draw maps of the immune/stromal ecosystem in more than 480 R-CHOPtreated DLBCL. Then, the identification of prognostic genesassociated to commonalities between cases in estimated fractions of specific microenvironment cytotypes-represented the first approach exploiting deconvolution to overcome the limits of GEP. Moreover, the prognostic power of the panel was validated by NanoString technology on two independent patient cohorts and demonstrated the feasibility of measuring the expression of TME-related transcripts directly on FFPE diagnostic biopsies (8). An innovative deconvolution framework using CIBERSORTx (29) to combinations of single-cell RNA-seq and bulk transcriptomic data has been very recently reported in de novo DLBCL. This approach recognized 49 distinct transcriptional states across 13 main tumor-associated cytotypes, including neutrophils, Mo, fibroblasts, and T cells (30). Patient subsets with peculiar enrichment in TME cell states also showed significant outcome differences that cannot be identified by classical transcriptomics. Consistently, the preliminary results from an independent investigation-applying an alternative algorithm to deconvolve $>3,000$ DLBCL from 13 transcriptomic and mutational datasets-identified four lymphoma subclasses with distinctive TME traits pairing recurrent genetic drivers of the tumor. Moreover, these new categories show different outcomes, independently of recent molecular classification (31). Such pioneering methods to unify subtle changes in rare TME populations with genetic features of the malignant counterpart provide unprecedented insights in DLBCL biology but require additional effort to prompt their clinical and even therapeutic applicability. Table 1 summarizes the major published studies exploring DLBCL TME over the last 20 years.

\section{BIOLOGICAL DETERMINANTS OF TME-RELATED PROGNOSTICATION}

Taken together, results from both low- and high-resolution dissection of DLBCL outlined aspects of TME dynamics that remained underestimated for years. Molecular signatures reflecting a predominant fibroblastic reaction and Mo infiltration correlated with better outcomes, thus generating a paradoxical interpretation of the common meaning of tumor-associated fibroblasts and Mo (36). Our recent work also emphasizes that biological differences between cases in the validation cohorts may impact on prognosis since they were homogeneously selected based on molecular and clinical parameters [i.e., the validation sets include only advanced-stage patients who have undergone standard front-line R-CHOP/R-CHOP-like regimens (9)].

From a biological point of view, ECM components as well as fibroblasts and Mo appear critically inter-chained as major cross-players of the structural and inflammatory machineries of SLO. Collagens, proteoglycans, glycoproteins, metalloproteinases, and matricellular proteins, such as SPARC and osteopontin, are synthesized by mesenchymal elements and partially by Mo, generating heterogeneous mixtures undergoing continuous remodeling under the pressure of tumor growth and inflammation (37). The deposition of non-cellular factors also mediates the activation of adhesion molecules and integrins (i.e., $\alpha \mathrm{V} \beta 3$ or $\alpha 6 \beta 4)$ that provide anchorage to Mo and T cells and possible antigen-independent stimulation of the BCR pathway in malignant cells (38). Paracrine gradients of cytokines and chemokines released by stromal and tumor cells themselves also drive the recruitment and the polarization of monocytes/Mo, $\mathrm{T}$ cells, DC, as well as other stromal elements with antigenpresenting capacity, such as follicular dendritic cells and fibroblastic reticular cells (FRC) (39-41). A number of preclinical studies indicated that accessory cells as neutrophils, stromal cells, monocytes, and $\mathrm{T}$ cells hold the capacity to modulate tumor survival. Neutrophils can be recruited by CXCL8-secreting tumor cells and, in turn, modulate tumor growth by secreting the proliferation-inducing ligand APRIL and up-regulating the NF$\mathrm{kB}$, STAT3, and p38 pathways via the Toll-like receptor 9 signal (42-44). Co-cultures of mouse stromal elements with primary DLBCL cells enhanced their clonogenicity as effect of both cellto-cell adhesion and paracrine mechanisms involving the B cell activating factor and the BCL2 axes $(45,46)$. Similarly, cells of monocytic origin were proved to prolong lymphoma cell survival by mechanisms that are still unclear (47). All these models, however, remain poorly representative of the in vivo complexity of tumor/TME interactions and far from explaining their influence on outcome to standard immunochemotherapy.

An additional influence of TME on lymphoma behavior involves the defective immune competence of effector cells. A PD-L1 overexpression by tumor and TME components is observable in a considerable fraction of DLBCL showing pools of exhausted PD-1 ${ }^{+} \mathrm{T}$ cells (48). The phagocytic activity of Mo and DC is likewise hampered by SIRP $\alpha$ stimulation after binding with CD47, which is up-regulated on tumor cells. Both these mechanisms encouraged the experimental use of new anti-PD-1 and anti-CD47 antibodies in relapsed/refractory DLBCL, aiming at restoring the specific immune function of TME $(49,50)$.

On the other hand, some in vitro and in vivo results suggest the ability of tumor cells to shape the composition of the surrounding milieu. For instance, genetically unstable DLBCL cells display reduced surface expression of $\mathrm{MHC}$ and CD58 molecules, thus lowering $\mathrm{T}$ cell and NK infiltration and cytotoxicity (51). Conversely, DLBCL-released lymphotoxins and TNF-alpha were 
TABLE 1 | List of studies assessing the prognostic implication of TME in DLBCL.

\begin{tabular}{|c|c|c|c|c|c|c|}
\hline Technique & Biomarker & $\begin{array}{l}\text { TME } \\
\text { component }\end{array}$ & $\begin{array}{l}\text { Number of } \\
\text { cases/material }\end{array}$ & Treatment & Prognostic implication & References \\
\hline \multirow[t]{7}{*}{$\mathrm{IHC} / \mathrm{IF}$} & $\begin{array}{l}\text { CD1a+ (DC) } \\
\text { Granzyme B+ (T cells) }\end{array}$ & DC & 48/FFPE & CHOP/Rituximab & $\begin{array}{l}\text { CD1a+: favorable OS } \\
\text { Granzyme B+: favorable OS }\end{array}$ & (23) \\
\hline & $\begin{array}{l}\text { SPARC } \\
\text { CD68 }\end{array}$ & Stromal cells & 262/FFPE & R-CHOP/R-CHOP-like & $\begin{array}{l}\text { SPARC: favorable OS and FS } \\
\text { CD68: not significant }\end{array}$ & (13) \\
\hline & $\begin{array}{l}\text { SPARC } \\
\text { FN1 }\end{array}$ & Stromal cells & 173/FFPE & $\begin{array}{l}\text { CHOP/CHOP-like } \\
\text { R-CHOPNACOP }\end{array}$ & SPARC/FN1: favorable OS & $(14)$ \\
\hline & $\begin{array}{l}\text { FOXP3 } \\
\text { CD3 }\end{array}$ & T cells & 161/FFPE & $\mathrm{R}-\mathrm{CHOP}$ & FOXP3 and CD3: favorable & $(21)$ \\
\hline & $\begin{array}{l}\text { PD-1 } \\
\text { CD3 } \\
\text { PD-L1 }\end{array}$ & T cells & 414/FFPE & $\mathrm{R}-\mathrm{CHOP}$ & $\begin{array}{l}\text { CD3 }{ }^{\text {high } P D-1+: ~ u n f a v o r a b l e ~ O S ~} \\
\text { PD-1/PD-L1 interaction: } \\
\text { unfavorable OS }\end{array}$ & (32) \\
\hline & $\begin{array}{l}\text { PD-1 } \\
\text { LAG-3 } \\
\text { TIM-3 }\end{array}$ & T cells & 123/FFPE & R-CHOP/other & TIM-3: unfavorable OS and PFS & (33) \\
\hline & $\begin{array}{l}\text { CD68 } \\
\text { CD163 }\end{array}$ & Mo & 221/FFPE & CHOP/R-CHOP & $\begin{array}{l}\text { CD68: unfavorable OS and PFS } \\
\text { CD163: unfavorable OS and PFS }\end{array}$ & (34) \\
\hline $\begin{array}{l}\text { IHC } \\
\text { GEP }\end{array}$ & $\begin{array}{l}\text { CD68 } \\
\text { CD163 }\end{array}$ & Mo & $\begin{array}{l}\text { 181/FFPE (IHC) } \\
\text { 544/FF (GEP) }\end{array}$ & $\begin{array}{l}\text { R-chemo } \\
\text { Chemo }\end{array}$ & $\begin{array}{l}\text { R-chemo: favorable PFS and OS } \\
\text { Chemo: unfavorable PFS and OS }\end{array}$ & $(22)$ \\
\hline \multirow[t]{4}{*}{ GEP } & $\begin{array}{l}\text { Lymph node } \\
\text { T cell signatures }\end{array}$ & $\begin{array}{l}\text { Monocyte/Mo } \\
\text { NK } \\
\text { ECM } \\
\text { T cells }\end{array}$ & $42 / F F$ & $\begin{array}{l}\text { Anthracycline-based } \\
\text { regimens }\end{array}$ & - & $(10)$ \\
\hline & $\begin{array}{l}\text { Host response } \\
\text { signature }\end{array}$ & $\begin{array}{l}\text { T cells, } \\
\text { monocyte/Mo, } \\
\text { DC }\end{array}$ & 176/FF & $\mathrm{CHOP}$ & Unfavorable & $(7)$ \\
\hline & $\begin{array}{l}\text { Stromal-1 } \\
\text { Stromal-2 signatures }\end{array}$ & $\begin{array}{l}\text { ECM proteins } \\
\text { Mo } \\
\text { Vascular density }\end{array}$ & 414/FF & $\mathrm{CHOP} / \mathrm{R}-\mathrm{CHOP}$ & $\begin{array}{l}\text { Stromal-1: favorable } \\
\text { Stromal-2: unfavorable }\end{array}$ & (8) \\
\hline & LAMIS signature & Mo & 466/FFPE & R-CHOP/R-CHOP like & Unfavorable & (26) \\
\hline $\begin{array}{l}\text { RNA-seq } \\
\text { IHC }\end{array}$ & PD-L1 & Mo & $\begin{array}{l}\text { 702/FFPE (RNAseq) } \\
\text { 433/FFPE (IHC) }\end{array}$ & $\begin{array}{l}\text { R-CHOP vs. } \\
\text { obinutuzumab-CHOP } \\
\text { and } \\
\text { R-CHOP } \pm \text { bevacizumab }\end{array}$ & Favorable & (35) \\
\hline $\begin{array}{l}\text { Deconvolution } \\
\text { (CIBERSORT) }\end{array}$ & 45-TME gene panel & $\begin{array}{l}\text { Myofibroblasts } \\
\text { DC } \\
\text { CD4-T cells }\end{array}$ & $\begin{array}{l}\text { 482/FF } \\
215 / \mathrm{FFPE}\end{array}$ & R-CHOP/R-CHOP like & Favorable OS and PFS & (9) \\
\hline
\end{tabular}

reported to promote the proliferative attitude of podoplanin-, PD-L1/L2-positive fibroblasts, while lowering their ability to contract collagen fibers and attract cytotoxic T cells (52).

Overall, it is conceivable that the local extent of constitutional and reactive processes of both stromal and inflammatory nature shapes the final cellular composition of the affected lymph nodes, forming specialized contextures with topographical and functional identity (Figure 1). These niches may vary within the same tumor, across different tumor sites in the same patients, and between different patients, resulting in a relevant biological and outcome diversity. The application of innovative computational tools $(9,26)$ added texture to this picture in DLBCL, yet remaining elusive about the precise mechanisms and timing of TME-centered dynamics. The recognition of a single biological trait unifying the complexity of tumor/TME interactions is very challenging, owing to their potential variation at different disease stages and type of treatment. In fact, the favorable prognostic value observed for stromal/Mo signatures in DLBCL treated by chemo-immunotherapy may rely on the mechanism of rituximab action, which activates killing by the phagocytic capacity of resident immune cells, especially Mo (53). There is indeed growing interest in exploring the role of pure stromal axes, such as SDF-1/CXCR4, in sustaining B cell survival via BCR-independent mechanisms (54) and affecting their sensitiveness to BCR inhibitors (i.e., ibrutinib) and immune modulators (i.e., lenalidomide) with a known offtarget effect on both the stromal and the immune components of TME $(55,56)$.

\section{CONCLUSION AND FUTURE DIRECTIONS}

Enormous body of work based on new-generation technologies has produced low/medium-resolution data on the quality of tumor and its surrounding TME, to predict patient responsiveness to standard therapy. While the success of novel immunotherapies increases in other lymphoma subtypes, clinical 


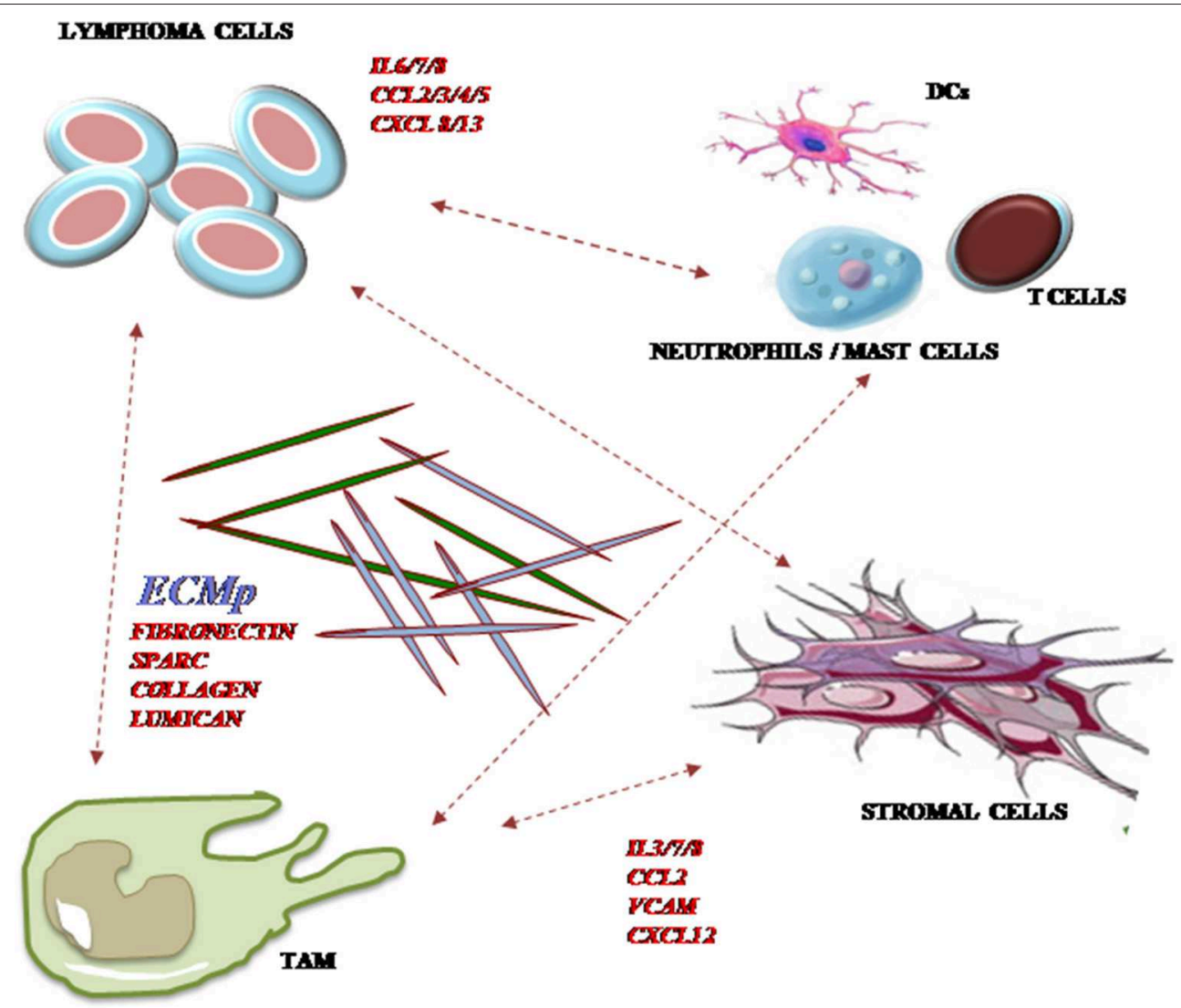

FIGURE 1 | Major cellular and non-cellular components of TME in DLBCL. A number of cellular elements of both immune and stromal origins generate intricate cell-to-cell and paracrine networks with tumor B cells. Reciprocal modulation occurs between malignant clones and tumor-associated macrophages (TAM), stromal and immune cells including neutrophils, mast cells, T cells, and dendritic cells (DC) through the expression of chemokines, cytokines, and extracellular matrix (ECM) component deposition. CCL, CC-motif chemokine ligand; CXCL, CXC-motif chemokine ligand; CXCR, CXC-motif chemokine receptor; ECM, extracellular matrix; IL, interleukin.

results are unsatisfactory in DLBCL. Therefore, characterization of TME is emerging as a critical step for strengthening the rationales of upcoming treatments or enriching subgroups of front-line responder patients. The implementation of computational techniques offers a chance to mine old bulk transcriptomic data and interrogate new sequencing records at a single-cell level. Moreover, the combination of innovative multidimensional applications of digital pathology is expected to provide deeper insights on the composition, function, and localization of immune and stromal determinants of DLBCL.

On the other hand, despite tremendous experimental efforts, it remains of critical importance to clarify (i) whether and how the tumor transcriptional, mutational, and immunogenic landscape influences the TME composition; (ii) how reciprocal stimuli between tumor and immune/stromal cells change as the disease progresses and under the influence of different drugs; and (iii) how the constitutive local feature of the SLO microenvironment influences tumor initiation and progression. Robust preclinical models and in vivo ultra-sensitive arrays to measure subtle TME changes will be necessary to answer these questions and translate future results to the clinical setting.

\section{AUTHOR CONTRIBUTIONS}

SC and GO discussed, designed, and conceptualized the review article. SC, GO, and MV wrote and edited the article. AG provided the first revision of the article. Literature review was performed by TS, GL, and AN. AN and TS respectively constructed Figure 1 and Table 1. SC and SP performed the final revision of the article.

\section{FUNDING}

This work was supported by Italian Ministry of Health (RRC2018-2020 to SC) and AIRC 5x1000 (grant no. 21198 to SP). 


\section{REFERENCES}

1. Scott DW, Gascoyne RD. The tumour microenvironment in B cell lymphomas. Nat Rev Cancer. (2014) 14:517-34. doi: 10.1038/nrc3774

2. Swerdlow SH. WHO classification of tumours of haematopoietic and lymphoid tissues. Available online at: http://publications.iarc.fr/Book-AndReport-Series/Who-Iarc-Classification-Of-Tumours/Who-ClassificationOf-Tumours-Of-Haematopoietic-And-Lymphoid-Tissues-2017 (accessed February 15, 2018).

3. Scott DW, Wright GW, Williams PM, Lih C-J, Walsh W, Jaffe ES, et al. Determining cell-of-origin subtypes of diffuse large B-cell lymphoma using gene expression in formalin-fixed paraffin-embedded tissue. Blood. (2014) 123:1214-17. doi: 10.1182/blood-2013-11-536433

4. Reddy A, Zhang J, Davis NS, Moffitt AB, Love CL, Waldrop A, et al. Genetic and functional drivers of diffuse large B cell lymphoma. Cell. (2017) 171:48194.e15. doi: 10.1016/j.cell.2017.09.027

5. Schmitz R, Wright GW, Huang DW, Johnson CA, Phelan JD, Wang JQ, et al. Genetics and pathogenesis of diffuse large B-cell lymphoma. N Engl J Med. (2018) 378:1396-407. doi: 10.1056/NEJMoa1801445

6. Chapuy B, Stewart C, Dunford AJ, Kim J, Kamburov A, Redd RA, et al. Molecular subtypes of diffuse large B cell lymphoma are associated with distinct pathogenic mechanisms and outcomes. Nat Med. (2018) 24:679-90. doi: 10.1038/s41591-018-0016-8

7. Monti S, Savage KJ, Kutok JL, Feuerhake F, Kurtin P, Mihm M, et al. Molecular profiling of diffuse large B-cell lymphoma identifies robust subtypes including one characterized by host inflammatory response. Blood. (2005) 105:1851-61. doi: 10.1182/blood-2004-07-2947

8. Lenz G, Wright G, Dave SS, Xiao W, Powell J, Zhao H, et al. Stromal gene signatures in large-B-cell lymphomas. N Engl J Med. (2008) 359:2313-23. doi: 10.1056/NEJMoa0802885

9. Ciavarella S, Vegliante MC, Fabbri M, De Summa S, Melle F, Motta G, et al. Dissection of DLBCL microenvironment provides a gene expression-based predictor of survival applicable to formalin-fixed paraffin-embedded tissue. Ann Oncol. (2018) 29:2363-70. doi: 10.1093/annonc/mdy450

10. Alizadeh AA, Eisen MB, Davis RE, Ma C, Lossos IS, Rosenwald A, et al. Distinct types of diffuse large B-cell lymphoma identified by gene expression profiling. Nature. (2000) 403:503-11. doi: 10.1038/35000501

11. Malhotra D, Fletcher AL, Astarita J, Lukacs-Kornek V, Tayalia P, Gonzalez SF, et al. Transcriptional profiling of stroma from inflamed and resting lymph nodes defines immunological hallmarks. Nat Immunol. (2012) 13:499-510. doi: $10.1038 /$ ni. 2262

12. Rosenwald A, Wright G, Chan WC, Connors JM, Campo E, Fisher RI, et al. The use of molecular profiling to predict survival after chemotherapy for diffuse large-B-cell lymphoma. N Engl J Med. (2002) 346:1937-47. doi: 10.1056/NEJMoa012914

13. Meyer PN, Fu K, Greiner T, Smith L, Delabie J, Gascoyne R, et al. The stromal cell marker SPARC predicts for survival in patients with diffuse large Bcell lymphoma treated with rituximab. Am J Clin Pathol. (2011) 135:54-61. doi: 10.1309/AJCPJX4BJV9NLQHY

14. Brandt S, Montagna C, Georgis A, Schüffler PJ, Bühler MM, Seifert B, et al. The combined expression of the stromal markers fibronectin and SPARC improves the prediction of survival in diffuse large B-cell lymphoma. Exp Hematol Oncol. (2013) 2:27. doi: 10.1186/2162-3619-2-27

15. Keane C, Gill D, Vari F, Cross D, Griffiths L, Gandhi M. CD4+ Tumor infiltrating lymphocytes are prognostic and independent of R-IPI in patients with DLBCL receiving R-CHOP chemo-immunotherapy. Am J Hematol. (2013) 88:273-6. doi: 10.1002/ajh.23398

16. Malaponte G, Hafsi S, Polesel J, Castellano G, Spessotto P, Guarneri C, et al. Tumor microenvironment in diffuse large Bcell lymphoma: matrixmetalloproteinases activation is mediated by osteopontin overexpression. Biochim Biophys Acta. (2016) 1863:483-9. doi: 10.1016/j.bbamcr.2015.09.018

17. Shen L, Gao Y, Liu Y, Zhang B, Liu Q, Wu J, et al. PD-1/PD-L pathway inhibits M.tb-specific CD4+ T-cell functions and phagocytosis of macrophages in active tuberculosis. Sci Rep. (2016) 6:38362. doi: 10.1038/srep38362

18. Kridel R, Steidl C, Gascoyne RD. Tumor-associated macrophages in diffuse large B-cell lymphoma. Haematologica. (2015) 100:143-5. doi: 10.3324/haematol.2015.124008
19. Cai Q, Liao H, Lin S, Xia Y, Wang X, Gao Y, et al. High expression of tumor-infiltrating macrophages correlates with poor prognosis in patients with diffuse large B-cell lymphoma. Med Oncol. (2012) 29:2317-22. doi: 10.1007/s12032-011-0123-6

20. Hasselblom S, Hansson U, Sigurdardottir M, Nilsson-Ehle H, Ridell B, Andersson P-O. Expression of CD68 tumor-associated macrophages in patients with diffuse large B-cell lymphoma and its relation to prognosis. Pathol Int. (2008) 58:529-32. doi: 10.1111/j.1440-1827.2008.02268.x

21. Coutinho R, Clear AJ, Mazzola E, Owen A, Greaves P, Wilson A, et al. Revisiting the immune microenvironment of diffuse large B-cell lymphoma using a tissue microarray and immunohistochemistry: robust semi-automated analysis reveals $\mathrm{CD} 3$ and FoxP3 as potential predictors of response to RCHOP. Haematologica. (2015) 100:363-9. doi: 10.3324/haematol.2014.110189

22. Riihijärvi S, Fiskvik I, Taskinen M, Vajavaara H, Tikkala M, Yri O, et al. Prognostic influence of macrophages in patients with diffuse large B-cell lymphoma: a correlative study from a nordic phase II trial. Haematologica. (2015) 100:238-45. doi: 10.3324/haematol.2014.113472

23. Chang K-C, Huang G-C, Jones D, Lin Y-H. Distribution patterns of dendritic cells and $\mathrm{T}$ cells in diffuse large B-cell lymphomas correlate with prognoses. Clin Cancer Res. (2007) 13:6666-72. doi: 10.1158/1078-0432.CCR-07-0504

24. Wada N, Zaki MAA, Hori Y, Hashimoto K, Tsukaguchi M, Tatsumi Y, et al. Tumour-associated macrophages in diffuse large B-cell lymphoma: a study of the osaka lymphoma study group. Histopathology. (2012) 60:313-9. doi: 10.1111/j.1365-2559.2011.04096.x

25. Marchesi F, Cirillo M, Bianchi A, Gately M, Olimpieri OM, Cerchiara E, et al. High density of CD68+/CD163+ tumour-associated macrophages (M2TAM) at diagnosis is significantly correlated to unfavorable prognostic factors and to poor clinical outcomes in patients with diffuse large B-cell lymphoma. Hematol Oncol. (2015) 33:110-12. doi: 10.1002/hon.2142

26. Staiger AM, Altenbuchinger M, Ziepert M, Kohler C, Horn H, Huttner $\mathrm{M}$, et al. A novel lymphoma-associated macrophage interaction signature (LAMIS) provides robust risk prognostication in diffuse large B-cell lymphoma clinical trial cohorts of the DSHNHL. Leukemia. (2019) 34:543-52. doi: 10.1038/s41375-019-0573-y

27. Newman AM, Liu CL, Green MR, Gentles AJ, Feng W, Xu Y, et al. Robust enumeration of cell subsets from tissue expression profiles. Nat Methods. (2015) 12:453-7. doi: 10.1038/nmeth.3337

28. Gentles AJ, Newman AM, Liu CL, Bratman SV, Feng W, Kim D, et al. The prognostic landscape of genes and infiltrating immune cells across human cancers. Nat Med. (2015) 21:938-45. doi: 10.1038/nm.3909

29. Newman AM, Steen CB, Liu CL, Gentles AJ, Chaudhuri AA, Scherer F, et al. Determining cell type abundance and expression from bulk tissues with digital cytometry. Nat Biotechnol. (2019) 37:773-82. doi: 10.1038/s41587-019-0114-2

30. Steen C. An Atlas of Clinically-Distinct Tumor Cellular Ecosystems in Diffuse Large B Cell Lymphoma. (2019). Available online at: https://ash.confex.com/ ash/2019/webprogram/Paper129461.html (accessed December 19, 2019).

31. Cerchietti L. Microenvironmental Signatures Reveal Biological Subtypes of Diffuse Large B-Cell Lymphoma (DLBCL) Distinct From Tumor Cell Molecular Profiling. (2019). Available online at: https://ash.confex.com/ash/ 2019/webprogram/Paper128889.html (accessed December 19, 2019).

32. Li L, Sun R, Miao Y, Tran T, Adams L, Roscoe N, et al. PD-1/PD-L1 expression and interaction by automated quantitative immunofluorescent analysis show adverse prognostic impact in patients with diffuse large B-cell lymphoma having T-cell infiltration: a study from the International DLBCL Consortium Program. Mod Pathol. (2019) 32:741-54. doi: 10.1038/s41379-0180193-5

33. Chen BJ, Dashnamoorthy R, Galera P, Makarenko V, Chang H, Ghosh $\mathrm{S}$, et al. The immune checkpoint molecules PD-1, PD-L1, TIM-3 and LAG-3 in diffuse large B-cell lymphoma. Oncotarget. (2019) 10:2030-40. doi: 10.18632/oncotarget.26771

34. Li YL, Shi ZH, Wang $\mathrm{X}$, Gu KS, Zhai ZM. Tumorassociated macrophages predict prognosis in diffuse large B-cell lymphoma and correlation with peripheral absolute monocyte count. BMC Cancer. (2019) 19:1049. doi: 10.1186/s12885-0196208-x

35. McCord R, Bolen CR, Koeppen H, Kadel EE, Oestergaard MZ, Nielsen T, et al. PD-L1 and tumor-associated macrophages in de novo DLBCL. Blood Adv. (2019) 3:531-40. doi: 10.1182/bloodadvances.2018020602 
36. Haro M, Orsulic S. A paradoxical correlation of cancer-associated fibroblasts with survival outcomes in B-cell lymphomas and carcinomas. Front Cell Dev Biol. (2018) 6:98. doi: 10.3389/fcell.2018.00098

37. Cacciatore M, Guarnotta C, Calvaruso M, Sangaletti S, Florena AM, Franco V, et al. Microenvironment-centred dynamics in aggressive B-cell lymphomas. Adv Hematol. (2012) 2012:1-12. doi: 10.1155/2012/138079

38. Wang $H$, Leavitt $L$, Ramaswamy $R$, Rapraeger AC. Interaction of syndecan and alpha6beta4 integrin cytoplasmic domains: regulation of ErbB2-mediated integrin activation. J Biol Chem. (2010) 285:13569-79. doi: 10.1074/jbc.M110.102137

39. Fletcher AL, Malhotra D, Turley SJ. Lymph node stroma broaden the peripheral tolerance paradigm. Trends Immunol. (2011) 32:12-8. doi: 10.1016/j.it.2010.11.002

40. Chang JE, Turley SJ. Stromal infrastructure of the lymph node and coordination of immunity. Trends Immunol. (2015) 36:30-9. doi: 10.1016/j.it.2014.11.003

41. Fletcher AL, Acton SE, Knoblich K. Lymph node fibroblastic reticular cells in health and disease. Nat Rev Immunol. (2015) 15:350-61. doi: 10.1038/nri3846

42. Schwaller J, Schneider P, Mhawech-Fauceglia P, McKee T, Myit S, Matthes $\mathrm{T}$, et al. Neutrophil-derived APRIL concentrated in tumor lesions by proteoglycans correlates with human B-cell lymphoma aggressiveness. Blood. (2007) 109:331-8. doi: 10.1182/blood-2006-02-001800

43. MacKay F, Schneider P. Cracking the BAFF code. Nat Rev Immunol. (2009) 9:491-502. doi: 10.1038/nri2572

44. Nie M, Yang L, Bi X, Wang Y, Sun P, Yang H, et al. Neutrophil extracellular traps induced by IL8 promote diffuse large B-cell lymphoma progression via the TLR9 signaling. Clin Cancer Res. (2019) 25:1867-79. doi: 10.1158/1078-0432.CCR-18-1226

45. Lwin T, Hazlehurst LA, Li Z, Dessureault S, Sotomayor E, Moscinski LC, et al. Bone marrow stromal cells prevent apoptosis of lymphoma cells by upregulation of anti-apoptotic proteins associated with activation of NF-кB (RelB/p52) in non-Hodgkin's lymphoma cells. Leukemia. (2007) 21:1521-31. doi: 10.1038/sj.leu.2404723

46. Singh RR, Kunkalla K, Qu C, Schlette E, Neelapu SS, Samaniego F, et al. ABCG2 is a direct transcriptional target of hedgehog signaling and involved in stroma-induced drug tolerance in diffuse large B-cell lymphoma. Oncogene. (2011) 30:4874-86. doi: 10.1038/onc.2011.195

47. Mueller CG, Boix C, Kwan W-H, Daussy C, Fournier E, Fridman WH, et al. Critical role of monocytes to support normal B cell and diffuse large B cell lymphoma survival and proliferation. J Leukoc Biol. (2007) 82:567-75. doi: 10.1189/jlb.0706481

48. Song MK, Park BB, Uhm J. Understanding immune evasion and therapeutic targeting associated with PD-1/PD-L1 pathway in diffuse large B-cell lymphoma. Int J Mol Sci. (2019) 20:1326. doi: 10.3390/ijms20061326
49. Ansell SM, Minnema MC, Johnson P, Timmerman JM, Armand P, Shipp MA, et al. Nivolumab for relapsed/refractory diffuse large B-cell lymphoma in patients ineligible for or having failed autologous transplantation: a singlearm, phase II study. J Clin Oncol. (2019) 37:481-9. doi: 10.1200/JCO.18.00766

50. Advani R, Flinn I, Popplewell L, Forero A, Bartlett NL, Ghosh N, et al. CD47 Blockade by Hu5F9-G4 and rituximab in non-hodgkin's lymphoma. N Engl J Med. (2018) 379:1711-21. doi: 10.1056/NEJMoa1807315

51. Rimsza LM, Roberts RA, Miller TP, Unger JM, LeBlanc M, Braziel RM, et al. Loss of MHC class II gene and protein expression in diffuse large B-cell lymphoma is related to decreased tumor immunosurveillance and poor patient survival regardless of other prognostic factors: a follow-up study from the leukemia and lymphoma molecular profiling project. Blood. (2004) 103:4251-8. doi: 10.1182/blood-2003-072365

52. Apollonio B, Jarvis P, Phillips B, Kuhnl A, Salisbury J, Zacharioudakis G, et al. Diffuse large B-cell lymphoma remodels the fibroblastic reticular network that acquires aberrant immunosuppressive capabilities; implications for the regulation of anti-tumor immunity in the immuno-oncology era. Blood. (2018) 132(Suppl.1):675. doi: 10.1182/blood-2018-99-116409

53. Glennie MJ, French RR, Cragg MS, Taylor RP. Mechanisms of killing by anti-CD20 monoclonal antibodies. Mol Immunol. (2007) 44:3823-37. doi: 10.1016/j.molimm.2007.06.151

54. Casola S, Perucho L, Tripodo C, Sindaco P, Ponzoni M, Facchetti F. The Bcell receptor in control of tumor B-cell fitness: biology and clinical relevance. Immunol Rev. (2019) 288:198-213. doi: 10.1111/imr.12738

55. Kotla V, Goel S, Nischal S, Heuck C, Vivek K, Das B, et al. Mechanism of action of lenalidomide in hematological malignancies. J Hematol Oncol. (2009) 2:36. doi: 10.1186/1756-8722-2-36

56. Ping L, Ding N, Shi Y, Feng L, Li J, Liu Y, et al. The Bruton's tyrosine kinase inhibitor ibrutinib exerts immunomodulatory effects through regulation of tumor-infiltrating macrophages. Oncotarget. (2017) 8:39218-29. doi: 10.18632 /oncotarget.16836

Conflict of Interest: The authors declare that the research was conducted in the absence of any commercial or financial relationships that could be construed as a potential conflict of interest.

Copyright (c) 2020 Opinto, Vegliante, Negri, Skrypets, Loseto, Pileri, Guarini and Ciavarella. This is an open-access article distributed under the terms of the Creative Commons Attribution License (CC BY). The use, distribution or reproduction in other forums is permitted, provided the original author(s) and the copyright owner(s) are credited and that the original publication in this journal is cited, in accordance with accepted academic practice. No use, distribution or reproduction is permitted which does not comply with these terms. 